Z. klin. Chem. u. klin. Biochem.

7. Jg., S. 28-31, Januar 1969

\title{
Thyroxinbindungskapazität und Jodgehalt des Serums bei Anwendung jodhaltiger Röntgenkontrastmittel
}

\author{
Von H. L. KRÜSKEMPER, K. D. MORGNER und F. ZIE⿺̨SKE \\ Abteilung II (Klinische Endokrinologie), Mediziniscbe Klinik und Institut für Nuklearmedizin, \\ Radiologisches Zentrum der. Medizinischen Hocbscbule Hannover
}

(Eingegangen am 16. August 1968)

\begin{abstract}
Bei männlichen Versuchspersonen ohne Störung der Schilddrüsenfunktion wurden der Serumjodgehalt und der Serum- ${ }^{131}$ J-Trijodthyronintest nach Gabe jodhaltiger Röntgenkontrastmittel zur Infusionsurographie, Cholecystographie und Lymphographie gemessen. Die Eliminationskurven der Kontrastmittel unterschieden sich in typischer Weise. Das Resultat des Serum- $T_{3}$-Tests war unabhängig von Art und Menge des verwendeten jodhaltigen Kontrastmittels. Da die Bindungskapazität des Serums für Thyroxin durch die untersuchten Kontrastmittel nicht verändert wurde, wird gefolgert, daß der Serum- $\mathrm{T}_{3}$-Test in Fällen mit Kontrastmittelkontamination seinen diagnostischen Wert nicht verliert.
\end{abstract}

\section{Thyroxine-binding capacity and iodine content of serum during the use of iodine-containing $X$-ray' contrast agents}

In male subjects without thyroid disease the iodine content of serum and the resin uptake of $\mathrm{I}^{131}$-triiodothyronine $\left(\mathrm{T}_{3}\right.$-test) were measured following the application of iodine-containing toentgenographic dyes for urography, cholegraphy and lymphography. The elimination patterns of these contrast media differ characteristically. Results of $T_{3}$-tests are independent of either the type or amount of iodinated contrast substance present in serum. Since the thyroxine-binding capacity of serum is not affected by contrast media, it can be concluded, that the $T_{3}$-test remains valid for diagnostic purposes in patients contaminated with iodine-containing roentgenographic dyes.

Die Bestimmung des proteingebundenen Jod ( $\left.\mathrm{PB}^{127} \mathrm{~J}\right)$ im Serum stellt einen der wichtigsten objektiven Parameter im Rahmen der Schilddrüsenfunktionsdiagnostik dar. Die generelle Anwendbarkeit dieses Tests wird jedoch dadurch eingeschränkt, daß außer Thyroxin und Trijodthyronin auch zahlreiche andere jodhaltige Verbindungen, die $\mathrm{zu}$ therapeutischen oder diagnostischen Zwecken appliziert werden, in die Messung des $\mathrm{PB}^{127} \mathrm{~J}$ eingehen können. Das gilt sowohl für diejenigen Methoden der $\mathrm{PB}^{127} \mathrm{~J}$-Bestimmung, die auf Eiweißfällung mit anschließender Jodanalyse beruhen, als auch für solche mit Anwendung eines Ionenaustauschers als erstem Schritt.

Eine kürzlich von Foldenauer und Mitarbeitern (1) mitgeteilte Liste von Substanzen, die als kontaminierende Agenzien berücksichtigt werden müssen, läßt die Vielfalt der Möglichkeiten und die Notwendigkeit einer besonders eingehenden Anamnese deutlich werden.

Aus unserem eigenen Untersuchungsmaterial ergaben sich (bei Ausschluß des diagnostisch anders gelagerte Probleme bietenden $\mathrm{PB}^{127} \mathrm{~J}$-Bereiches von $8-30 \mu \mathrm{g} /$ $100 \mathrm{~m} /$ ) folgende Zahlen zur Häufigkeit im engeren Sinne jodkontaminierter Seren: bei 7386 PB $^{127}$ J-Messungen an Patienten aus dem Klinikum und der nuklearmedizinischen und endokrinologischen Ambulanz (1. 1. 1967-15. 6. 1968) wurden 411 Werte $(5,56 \%)$ von über $30 \mu \mathrm{g} / 100 \mathrm{ml}$ ermittelt. Von diesen lagen etwa $25 \%$ im Bereich $30-100 \mu \mathrm{g} / 100 \mathrm{ml} ; 35 \%$ betrugen $100-500 \mu \mathrm{g} / 100 \mathrm{~m} l$ und die restlichen $40 \%$ wiesen $\mathrm{PB}^{127} \mathrm{~J}$-Werte von über $500 \mu \mathrm{g} / 100 \mathrm{ml}$ auf. Die (oft nachträglich eingehend wiederholte) Anamnese ließ nur in etwa einem Viertel der Fälle das kontaminierende Agens mit Sicherheit festlegen; mit Abstand wurden hier die jodhaltigen Röntgenkontrastmittel an erster Stelle genannt.

Angesichts solcher Zahlen erscheint es wünschenswert, bei Vorliegen einer Jodkontamination des Serums, vor allem mit Röntgenkontrastmitteln, auf andere objektive Parameter der Schilddrüsenfunktion mit ähnlichen Charakteristika wie die $\mathrm{PB}^{127} \mathrm{~J}$-Bestimmung (häufige Wiederholbarkeit, geringe Belastung des Patienten) ausweichen zu können.

Die in vitro-Messung der Serumbindung von markiertem Trijodthyronin (Serum- $\mathrm{T}_{3}$-Test) erfüllt weitestgehend diese Kriterien; extrathyreoidale Störfaktoren sind in erster Linie Verschiebungen im Eiweißspektrum des Serums, z. B. bei Erkrankungen der Leber und der Niere, bei Eiweißverlusten und unter spezifisch hormonellen Einflüssen auf thyroxinbindende Proteine durch Corticoide, Androgene oder Östrogene. Hierbei handelt es sich stets um quantitative Änderungen der Zahl der thyroxinbindenden Positionen und wohl nicht um Kompetition mit Thyroxin (bzw. Trijodthyronin) am Bindungsort. Das Verhalten des Serum- $T_{3}$-Tests in Seren mit Kontamination durch jodhaltige Röntgenkontrastmittel ist bislang lediglich orientierend und ohne Berücksichtigung des jeweiligen Serumjodgehaltes untersucht worden (2-5). Die Frage, ob quantitative Beziehungen des durch Kontrastmittel erhöhten Jodspiegels einerseits und dem Ergebnis des Serum- $T_{3}$ Tests andererseits bestehen, bedarf weiterer Klärung. Wir untersuchten daher an Patienten, welche Kontrastmittel zur Urographie, Cholecystographie bzw. Lympho- 
graphie erhalten hatten, in Parallelmessungen den Jodgehalt des Serums und die Höhe des Serum- $\mathrm{T}_{3}$ Tests.

\section{Methodik}

Die Untersuchungen wurden an euthyreoten männlichen Versuchspersonen im Alter von 20-50 Jahren mit normaler Funktion von Leber und Niere und normalem Elektrophoresediagramm durchgeführt. Die Lymphographien wurden nach Semikastration wegen maligner Hodentumoren zur Beurteilung evtl. Lymphknotenmetastasen vorgenommen. Sämtliche Blutentnahmen erfolgten mit Einmal-Spritzen und -Kanülen.

1. Der Serum-131 J-Trijodthyronin-Test (Serum- $\mathrm{T}_{3}-$ Test) wurde unter Verwendung von Abbott-Trisorb Diagnostikbestecken durchgeführt (Einzelheiten s. (6)).

2. Der Jodgebalt des Serums wurde (mit dem Auto Analyzer) nach der Vorschrift von BeNotrI und BeNorTI (7) bestimmt. Wir ermittelten den Gesamtjodgebalt nach Vorscreening und entsprechender Serumverdünnung. Eine Bestimmung des proteingebundenen ${ }^{127} \mathrm{~J}$, wie sie z. B. von FrISCHAUF und Mitarbeitern (8) nach Anwendung jodhaltiger Kontrastmittel durchgeführt wurde, etschien uns nicht sinnvoll, da es bei jeder $z$. $Z$. verfügbaren $\mathrm{Me}$ thode $z \mathrm{u}$ Jodverlusten (durch Ubergang ins Lösungsmittel bzw. Adsorption an den verwendeten Ionenaustauscher (9)) in Größenordnungen bis $z u$ einer Zehnerpotenz kommen kann, womit sowohl Aussagen über Abklinggeschwindigkeiten wie auch über den aktuellen Serumspiegel der Kontrastmittel fragwürdig werden könnten.

3. Infusionsurograpbie: mit einer Infusionsdauer von 6-10 Min. wurde 30proz. Urovison (20,7\% Natrium- und 9,3\% Methylglukaminsalz der N,N'-Diacetyl-3,5-diamino-2,4,6-trijodbenzoesäure; Jodgehalt $168 \mathrm{mg} / \mathrm{ml}$ ) in einer Dosis von $2 \mathrm{ml} / \mathrm{kg}$ infundiert. Blutentnahmen erfolgten vor Beginn der Infusion, $10 \mathrm{Min}$. nach Infusionsende, weiter nach 1, 3, 5, 8 und 24 Stdn. und anschließend täglich einmal.

4. Cholecystograpbie: die Versuchspersonen erhielten $20 \mathrm{ml}$ Biligrafin forte (Methylglukaminsalz des Adipinsäure-bis-[3-carboxy2,4,6-trijodanilid]; $250 \mathrm{mg} \mathrm{Jod} / \mathrm{ml}$ ). Die Blutentnahmen zur Messung von Gesamtjodgehalt und Serum- $\mathrm{T}_{3}$-Test exfolgten wie unter 3. beschrieben.

5. Lymphographie: die Untersuchungen wurden mit Lipiodol Ultrafluid (Fettsäureäthylester des jodierten Oleum Papaveris; Jodgehalt $480 \mathrm{mg} / \mathrm{ml}$ ) durchgeführt. In jedes Bein wurden $10 \mathrm{ml}$ infundiert. Die Infusionsgeschwindigkeit betrug $0,1 \mathrm{~m} / \mathrm{Min}$. Der Zeitpunkt der Blutentnahme ist der Abbildung $3 \mathrm{zu}$ entnehmen.

6. Kontrollversuche: in einer Gruppe von 8 gesunden männlichen Versuchspersonen wurden nach 0,7 und 14 Tagen der PB $^{127} \mathrm{~J}$ Wert und der Serum- $T_{3}=$ Test gemessen, um das Ausmaß der Spontanschwankungen dieser Parameter zu tabellieren.

\section{Ergebnisse und Besprechungen}

\section{Infusionsurographie}

Die Ergebnisse unserer Untersuchungen an Patienten, bei denen eine Infusionsurogtaphie durchgeführt wurde, sind in Abbildung 1 dargestellt. Die im Rahmen eines Infusionsurogramms zugeführte Jodmengge beträgt bei Erwachsenen etwa $20-25 \mathrm{~g}$ (168 mg Jod/ml Urovison; $2 \mathrm{~m} / / \mathrm{kg}$ ). 10 Min. nach Infusionsende war in allen Fällen der Jodgehalt im Serum auf Werte zwischen 200 und $300 \mathrm{mg} / 100 \mathrm{ml}$ angestiegen. Entsprechend der hohen Ausscheidungsgeschwindigkeit nierengängiger Kontrastmittel fiel der Serum-Jodspiegel sehr rasch ab; er betrug 48 Stdn. nach dem Infusionsurogramm im
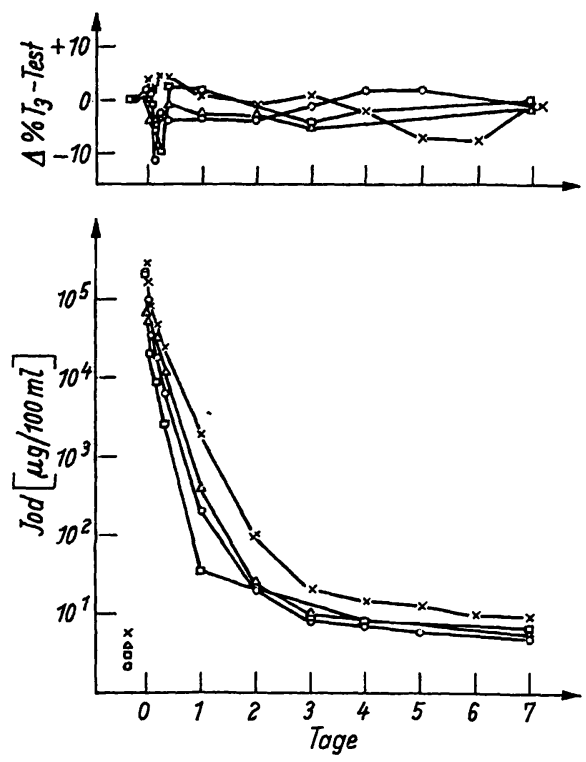

Abb. 1

Jodgehalt im Serum und Serum- $T_{2}-$ Test nach Infusionsurographie (Urovison)

Abszisse: Zeit in Tagen; Ordinate: Jodgehalt in $\mu \mathrm{g} / 100 \mathrm{~m} l$ logarithmisch; Abweichungen im Serum- $\mathrm{T}_{3}-$ Test $(\%)$

Mittel $46 \mu \mathrm{g} / 100 \mathrm{~m} /$. Der weitere Verlauf der Eliminationskurve ist wesentlich flacher, was an die Möglichkeit denken läßt, daß ein geringer Anteil des Kontrastmittels im Gewebe gespeichert, relativ langsam freigesetzt und schließlich auch über die Niere ausgeschieden wird. 7 Tage nach der Kontrastmittelinfusion war bei unseren Versuchspersonen der Jodgehalt im Serum auf $6,5 \mu \mathrm{g} / 100 \mathrm{~m} l \mathrm{im}$ Mittel gesunken; der entsprechende Mittelwert vor der Kontrastmittelanwendung betrug $5,7 \mu \mathrm{g} / 100 \mathrm{~m} l$.

Der Serum- $\mathrm{T}_{3}$-Test lag bei allen Versuchspersonen vor der Untersuchung im Normalbereich (Mittelwert: $54,9 \%$ ). In den Abbildungen 1 bis 3 wurde so verfahren, $\mathrm{da} \beta$ die im Serum- $\mathrm{T}_{3}$-Test gemessenen Werte in bezug zum Ausgangswert bei jedem einzelnen Patienten gesetzt wurden; dargestellt wird jeweils die Abweichung (in \%) zum individuellen Erstwert. Nach Infusionsurographie traten Schwankungen auf, die in einem Bereich von $+4 \%$ bis $-12 \%$ um den Ausgangswert streuen. Diese Schwankungen sind während der ersten 24 Stdn. nach dem Urogramm am deutlichsten. Eine Beeinflussung des Resultats des Serum- $\mathrm{T}_{3}$-Tests durch Urovison in einem weiten Konzentrationsbereich läßt sich jedoch nicht nachweisen; die Bindungskapazität des Serums für Thyroxin bleibt praktisch unverändert.

\section{Cholecystographie}

In Abbildung 2 sind die Ergebnisse unserer Untersuchungen nach Gabe von Biligrafin zusammengestellt. Die zugeführte Jodmenge betrug in allen Fällen $5 \mathrm{~g} .10 \mathrm{Min}$. nach Injektionsende lag der Gesamtjodgehalt des Serums bei Werten von $30-40 \mathrm{mg} / 100 \mathrm{~m}$. Die Elimination erfolgte dann wesentlich langsamer als oben für die nierengängigen Kontrastmittel beschrieben wurde. Nach 2 Tagen ist erst ein Abfall auf etwas mehr 

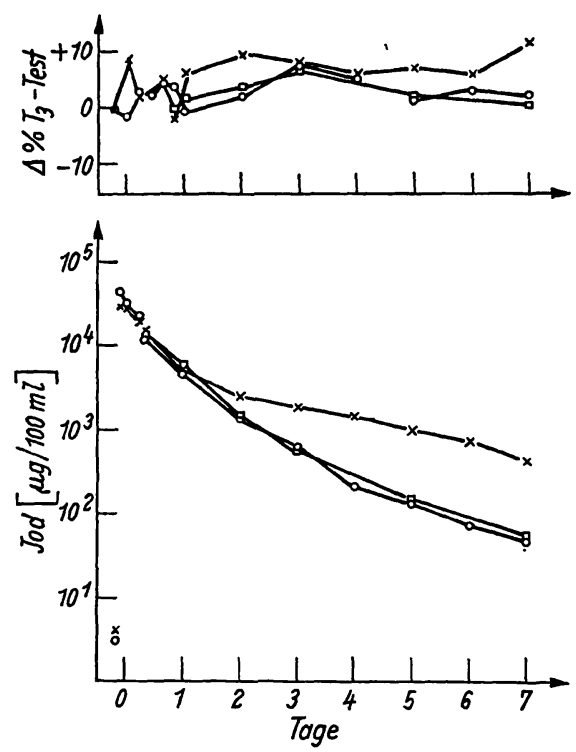

Abb. 2

Jodgehalt im Serum und Serum-Ts-Test nach Cholecystographie

Abszisse: Zeit in Tagen; Ordinate:Jodgehalt in $\mu \mathrm{g} / 100 \mathrm{ml}$ logarithmisch; Abweichungen im Serum- $T_{3}$-Test (\%)

als $1 \mathrm{mg} / 100 \mathrm{ml}$ (im Mittel) erfolgt, einen Wert, der den entsprechenden Jodspiegel nach Urographie um fast 2 Zehnerpotenzen übertrifft. Dieser Unterschied zwischen Urovison und Biligrafin, der im weiteren Verlauf des Versuches noch deutlicher wird, geht zweifellos in erster Linie auf die starke Bindung von Biligrafin an Serumproteine (9) zurück. Inwieweit zusätzlich eine Reabsorption über die Gallenwege ausgeschiedenen Kontrastmittels aus dem Darm eine Rolle spielt, muß noch offenbleiben.

Für den Serum- $T_{3}$-Test ergab sich ein ähnliches Bild wie bei Urovison, insofern als auch hier (bei einem mittleren Ausgangswert von 50\%) nach Applikation von Biligrafin zwar Schwankungen ( $-2 \%$ bis $+14 \%$ ) des Testresultates, jeweils keine gerichtete, auf den jeweiligen Jodspiegel beziehbare und reproduzierbare Beeinflussung des Serum- $\mathrm{T}_{3}$-Tests durch Biligrafin gefunden wurden. Auch Biligrafin verändert somit die Thyroxin-Bindungskapazität von Serum nicht.

\section{Lymphographie}

Der zeitliche Verlauf im Verhalten des Blutjodspiegels nach Durchführung einer Lymphographie unterscheidet sich wesentlich von dem nach Uro- oder Cholecystographie. Der Jodspiegel im Serum lag $10 \mathrm{Min}$. nach Infusionsende, d. h. mehr als $2 \mathrm{Stdn}$. nach Infusionsbeginn, wobei eine Jodmenge von 9,6 g zugeführt wurde, erst bei etwa $25 \mu \mathrm{g} / 100 \mathrm{ml}$, $6 \mathrm{Stdn}$. später bei etwa 100 bis $300 \mu \mathrm{g} / 100 \mathrm{ml}$. Dieser relativ langsame Anstieg des Jodgehalts im Blut hielt bis zum 5. bis 7 . Tag nach der Infusion an. Anschließend wurden bis $z u$ einer Zeit von 3 Wochen nach der Infusion nahezu konstant bleibende Serumjodkonzentrationen gemessen (s. Abb. 3). Auch nach Lymphographie zeigte sich

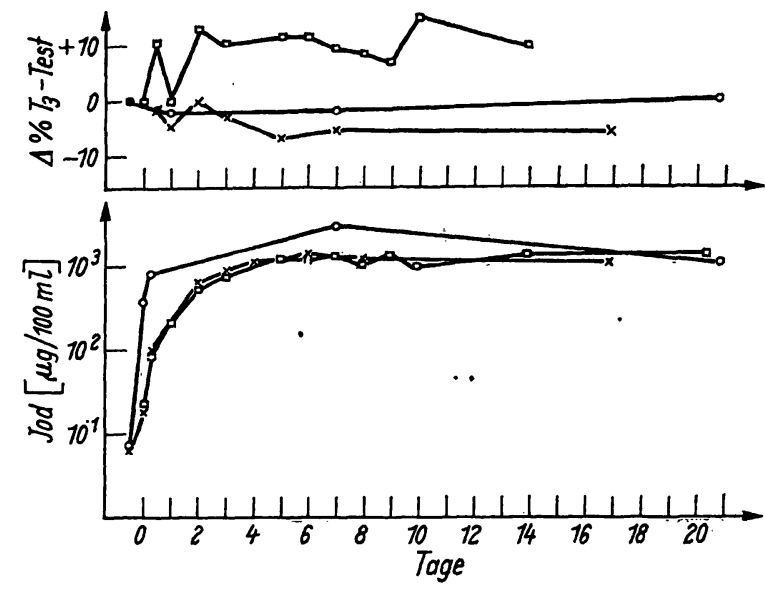

Abb. 3

Jodgehailt im Serum und Serum-T, Abszisse: Zeit in Tagen; Ordinate: Jodgehalt in $\mu \mathrm{g} / 100 \mathrm{ml}$ logarithmisch; Abweichungen im Serum-T,

kein typisches Verhalten des Serum- $\mathrm{T}_{\mathbf{3}}$-Tests; die gemessenen Schwankungen um den individuellen Ausgangswert betrugen hier -7 bis $+13 \%$. Auch das zur Lymphographie verwendete jodhaltige Kontrastmittel (Ester des jodierten Oleum Papaveris) besetzt somit keine thyroxinbindenden Positionen an Serumproteinen.

Unter methodisch gleichen Bedingungen. wurde, zusätzlich an einem Kollektiv von 8 gesunden júngen Männern die Frage der „Spontanschwankungen“ von $\mathrm{PB}^{127} \mathrm{~J}$ und Serum- $\mathrm{T}_{3}$-Test untersucht. Die Ergebnisse sind in Tabelle 1 zusammengestellt. Aus Doppelbestimmungen bei 1700 Einzelmessungen hat sich im übrigen ergeben, daß für den Serum- $\hat{T}_{3}$-Test eine Präzision von $\pm 5 \%$ angesetzt werden muß (6).

Einzelne Werte aus unseren Versuchsreihen überschreiten diese Präzisionsgrenze bzw. die nach den Daten der Tabelle $1 \mathrm{zu}$ erwartenden Spontanschwankungen im Serum- $\mathrm{T}_{3}$-Test. Wir können diese Einzelbefunde jedoch weder als unspezifische Jodeffekte im allgemeinen interpretieren noch auf die Verwendung eines der untersuchten Kontrastmittel im besonderen zurückzuführen, da die beobachteten Schwankungen völlig unsystematisch auftraten. Weder unter Lipiodol mit relativ langdauernd konstant hohem Jodspiegel

Tab. 1

Proteingebundenes ${ }^{127} \mathrm{~J}$ und Serum- $T_{3}-T$ est bei 8 gesunden männlichen Versuchspersonen, gemessen morgens nüchtern in wöchentlichen Versuchspersonen, gemessen morgens nü

\begin{tabular}{|c|c|c|c|c|c|c|}
\hline Vp. & \multicolumn{3}{|c|}{$\mathrm{PB}^{127} \mathrm{~J}(\mu \mathrm{g} / 100 \mathrm{~m} l)$} & \multicolumn{3}{|c|}{$0^{\text {Serum-T }} \mathrm{T}_{\mathrm{3}}-\mathrm{Test}(\%)$} \\
\hline 1 & 6,3 & 6,4 & 6,5 & 48,5 & 45,5 & 45,2 \\
\hline 2 & 6,3 & $6,0^{\circ}$ & 5,9 & 49,3 & 46,7 & 49,3 \\
\hline $\begin{array}{l}3 \\
4\end{array}$ & $\begin{array}{l}5,8 \\
7,6\end{array}$ & $\begin{array}{l}5,8 \\
7,4\end{array}$ & $\begin{array}{l}5,0 \\
6,8\end{array}$ & $\begin{array}{l}46,8 \\
42,7\end{array}$ & $\begin{array}{l}49,1 \\
44,2\end{array}$ & $\begin{array}{l}48,2 \\
46,3\end{array}$ \\
\hline 5 & 6,7 & 6,8 & 6,9 & 31,2 & 29,7 & 32,1 \\
\hline 6 & 5,8 & 6,1 & 7,4 & 33,0 & 42,5 & $43 ; 0$ \\
\hline 7 & 4,3 & 4,0 & 4,0 & 46,5 & 45,6 & 45,8 \\
\hline 8 & 4,3 & 4,2 & 4,3 & 56,1 & 50,4 & 55,7 \\
\hline $\begin{array}{c}\overline{\mathbf{x}} \\
\pm \mathrm{s}\end{array}$ & $\begin{array}{l}5,9 \\
1,1\end{array}$ & $\begin{array}{l}5,8 \\
1,2\end{array}$ & $\begin{array}{l}5,9 \\
1,3\end{array}$ & $\begin{array}{r}44,2 \\
9,3\end{array}$ & $\begin{array}{r}44,2 \\
6,4\end{array}$ & $\begin{array}{r}44,6 \\
6,7\end{array}$ \\
\hline
\end{tabular}


noch unter Urovison mit rasch ablaufendem Wechsel der Jodkonzentration über mehrere Zchnerpotenzen wurden typische Änderungen des Serum- $\mathrm{T}_{3}$-Tests gemessen. Unseres Erachtens sind dic beobachteten Schwankungen cher auf gewisse exogene Unterschicde in der Behandlung des entnommenen Blutes vor Durchführung des Serum- $T_{3}$-Tests zu bezichen, z. B. auf Zeitdifferenzen bis zur Scrumgewinnung auf Wechsel der Aufbewahrungstemperatur u. ã.
Unserc Ergebnisse zcigen, daß der Scrum- $T_{y}-T$ cst bei Kontamination mit jodhaltigen Röntgenkontrastmittcln verschiedener Struktur scinc Aussagekraft im wesentlichen behält, vor allem, wenn cr kurzfristig kontrolliert wird. Mit einer größeren Schwankungsspanne während der ersten 24 Stdn. nach Kontrastmittelapplikation sollte jedoch gerechnct werden, was vor allem beim Aufstellen diagnostischer Programme von Bedeutung wärc.

\section{Literatur}

1. Foldennuer, A., C. Meynen und P. Börm, Dtsch. med. Wschr. 91, 745 (1967). - 2. Bors-Svensson, J., J. Einisorn und $H$. Wicki.UNi), Acta cndocr. K'hvn 51, 1 (1966). - 3. Braveraman, J. E., A. E. Forster und R. A. Arky, J. nucl. Med. 8, 209 (1967). 4. Chisistofori, F. C. und G. G. Duncan, New. Engl. J. Med. 271, 564 (1964). - 5. Mrrchell, M. L., A. B. Harden und M. E. O'Roukke, J. clin. Endocr. 20, 1474 (1960). - 6. ZieLski, P.,
Vergleich des Thyroxin-Bindungs-Index mit der TrijodthyroninIonenaustauscherschwamm-Aufnahme. Mittcilungen der BYKMallinckrodt GmbH, Frankfurt (1968). - 7. Benorrs, J. und N. Benortr, Clin. Chem. New York 9, 408 (1963), - 8. FriscriAUp, H., N. Honety, H. Jesserpr, R. Kot'jaurek und N. StrupPEnell.1, Dtsch. Arch. klin. Med. 207, 329 (1961). - 9. Köddinc, R. und H. L. KRǗskPMPRK, Klin. Wschr. 46, 143 (1968).

Prof. Dr. H. J.. Krüskemper, Dr. K. D. Morgncr, Dr. F. Ziclskc Med. Hochschule 3000 Hannover, Podhiclskistr. 380 